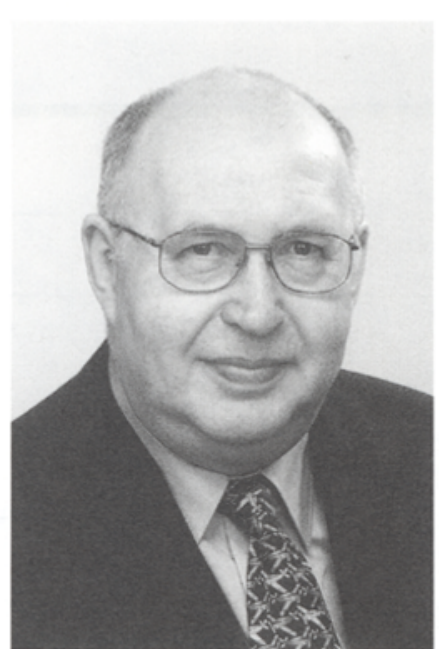

Jürgen Dodt

\section{Auf ein Neues}

Ein Editorial soll Sie, sehr geehrte Leserinnen und Leser, für das jeweilige neve - Heft unserer Zeitschrift "erwärmen"; es will vorweg fachlich besonders bedeutsam Erscheinendes akzentuieren und Ihre Aufmerksamkeit auf spezifische Inhalte lenken. Bei solcher Zielsetzung öfnet sich dem Editorial zum ersten Heft des 53. Jahrgangs (2003) ein recht weites Feld.

Da ist, erstens, darauf aufmerksam zu machen, dass der tradierte Titel unserer Zeitschrift - nach lebhafter Diskussion im vergangenen Jahr - mit diesem Heft durch den Untertitel "Fachzeitschrift für Geoinformation und Visualisierung" ergänzt/erweitert worden ist. Zweitens ist darauf hinzuweisen, dass die bisherige Rubrik "Panorama" vom Anfang des Heftes an den Schluss "verlagert" worden und aus der Verantwortung der $\mathrm{KN}$ Schriffleitung in die der Kirschbaum Verlagsredaktion übergegangen ist; unter dem neven Kurztitel "Geoinformation aktuell" wird hier - weiterhin, aber nun noch umfassender und schneller - über aktuelle Entwicklungen im Bereich der "kartographie-/GIS-relevanten" Wirtschaft und Behörden, über neve Erzeugnisse, Dienstleistungsangebote etc. berichtet werden. Als weitere Neverung muss, drittens, die Einrichtung eines so genannten Editorial Board, eines fachlich-wissenschaftlichen Beirates, hervorgehoben worden, der - wie in anderen Fachzeitschriften schon längst üblich die Schriftleitung namentlich bei der Beurteilung der eingehenden Fachaufsätze berät und so wesentlich zur nachhaltigen Qualitätssicherung der Zeitschrift beiträgt. Viertens ist ein Wechsel in der Schriffleitung der KN anzuzeigen: Nach dem (kurzfristigen) Rücktritt des gewählten Hauptschriftleiters, Prof. Dr. U. Fichtner, hat kommissarisch der "Alt-Haupt- schriffleiter", Prof. Dr. J. Dodt, die Funktion übernommen. - Wenn Sie sich über die vorangehend angesprochenen Punkte näher informieren wollen, lesen Sie "In eigener Sache" (ab. S. 42).

Nun zeichnet sich dieses Heft nicht nur durch formal-organisatorische Veränderungen und Neverungen aus, sondern es hat auch seine fachlich-inhaltliche "Besonderheit": Es handelt sich einmal mehr um ein thematisches "Schwerpunktheft", in dem die Mehrzahl der Aufsätze einem spezifischen Gebiet der Kartographie gewidmet ist - hier der "mobilen Kartographie". Gast-Editoren sind Frau Prof. Dr.-Ing. L. Meng und Herr Dipl.-Geogr. T. Reichenbacher, Lehrstuhl für Kartographie der TU München, denen die Schriffleitung für die ebenso produktive wie konstruktive und reibungslose Zusammenarbeit ganz herzlich dankt. Was Sie in diesem Heft lund auch im nächstenl über die mobile Kartographie erfahren können, erläutert lhnen das nachfolgende Editorial II. - Uber den engeren thematischen Schwerpunkt hinaus finden $\mathrm{Sie}$ in diesem Heft noch einen Aufsatz, der mit einem praxisorientierten Bericht über die GPS- und GIS-gestützte Erfassung der Weißeritzflut im Dresdner Stadtgebiet eine ganz andere semantische Dimension des Stichwortes "mobile Kartographie" erschließt und illustriert.

Schließlich: In der Rubrik DGfK-Nachrichten können Sie sich kurz über den bevorstehenden Iden 51.I Deutschen Kartographentag in Bad Krozingen bei Freiburg vom 27. bis 31. Mai informieren. Beachten Sie dazu in diesem Heft auch die entsprechende Beilage mit dem Anmeldeformular.

Ihr

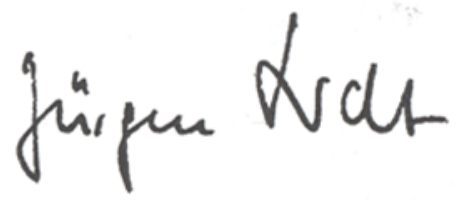

